\title{
Methodological challenges for the qualitative researcher: The use of a conceptual framework within a qualitative case study
}

Elizabeth Gregory

\section{How to cite this article}

Gregory, E. (2020) 'Methodological challenges for the qualitative researcher: The use of a conceptual framework within a qualitative case study'. London Review of Education, 18 (1): 126-141. https://doi.org/10.18546/LRE.18.1.09

Submission date: 25 February 2019

Acceptance date: 3 October 2019

Publication date: 1 March 2020

\section{Peer review}

This article has been peer reviewed through the journal's standard double blind peer review, where both the reviewers and authors are anonymized during review.

\section{Copyright}

(C) Copyright 2020 Gregory. This is an Open Access article distributed under the terms of the Creative Commons Attribution Licence (CC BY) 4.0 https://creativecommons.org/licenses/by/4.0/, which permits unrestricted use, distribution and reproduction in any medium, provided the original author and source are credited.

\section{Open access}

London Review of Education is a peer-reviewed open-access journal. 


\title{
Methodological challenges for the qualitative researcher: The use of a conceptual framework within a qualitative case study
}

\author{
Elizabeth Gregory* - University of Manchester, UK
}

\begin{abstract}
This article presents the MERITS Plus model, a conceptual framework developed during qualitative research into the process of academic transition and the impact of educational choices upon learner identity. The article considers some of the methodological challenges faced by qualitative researchers, and how effective the use of a conceptual framework might be in addressing these issues. The MERITS Plus model was developed and modified through two pilot studies and a piece of major fieldwork, the Learner, Identity and Transition Project (LITP), a qualitative case study conducted in a college of further education in England. Empirical data were collected through semi-structured narrative interviews with 24 learners studying either an A level or a BTEC programme, and from a focus group with teaching staff. The MERITS Plus model is a multilayered approach, comprising, first, a sixelement framework (Motivations, Expectations, Reality, Identity, Transition, and Stories and Synthesis) used to analyse the data, and, second, the use of Bourdieu's thinking tools to examine the complexities raised by the data. By combining these approaches, the study was able to present narratives directly by using the MERITS Plus model to create eight composite learner profiles drawn from the data to illustrate the range of different learner types found within one educational setting. Thus, the model is presented as a method of preserving the integrity of participant voice collected via qualitative methods, while allowing a systematic analysis of narratives both as individual stories and as products of particular social contexts.
\end{abstract}

Keywords: conceptual framework, learner identity, academic transition, further education, doctoral research

\section{Introduction and scope of the article}

This article reports on the development of a conceptual framework called the MERITS Plus model, exemplified through case study research conducted as part of a professional doctorate between 2011 and 2017. The study was entitled the Learner, Identity and Transition Project (LITP), and considered the impact of academic choices on the way learners narrate their experiences of transition. Two qualitative datasets were collected in one of the 231 general further education colleges in England (AoC, 2014), hereafter anonymized as Northlands College (NCFE), comprising the transcripts of individual narrative interviews with learners $(n=24)$ and of a staff focus group $(n=5)$. Student 
participants were prompted to talk about their experiences of moving from school to college through the use of three questions that asked them why they had selected their chosen course in preference to a different course or finding an apprenticeship, what their expectations of that course had been, and to what extent their experience had matched their expectations.

The study examined how participants narrated their experiences of the academic transition from Level 2 study to Level 3. For most learners in England aged 16-19, this transition marks the move from studying GCSEs within secondary school to undertaking three or four A levels or a vocational programme (most commonly, a BTEC in one single subject) within a sixth form or college over a two-year period. The participants in the LITP were drawn equally from these two academic routes, with 12 learners from each pathway taking part during the first year of studying their chosen course. The focus of the study was on these learner narratives, with the aim of presenting empirical data that specifically captured learner voice and added to a corpus that is under-represented, as little of the literature on youth transitions presents the experiences of young people who are doing well in education.

This article begins with a description of the MERITS Plus model and how it was used in the LITP, before considering the challenges inherent in the use of narrative interviews within a qualitative case study. Conceptual frameworks are discussed as a possible method of addressing these challenges, before a critical evaluation of such frameworks, and of the MERITS Plus model in particular. It is beyond the scope of the article to present in detail the findings of the study, although some aspects of the data are referred to in order to illustrate the use of the model and consider its effectiveness.

\section{The MERITS Plus model and its use in the LITP}

The MERITS Plus model is a conceptual framework developed over the course of the LITP and two preceding pilot studies. It consists of six different elements (Motivations, Expectations, Reality, Identity, Transition, and Stories and Synthesis) used to conduct a thematic and linguistic analysis of qualitative data collected during narrative interviews, plus a further layer of Bourdieusian analysis (see Table 1).

The model was initially developed from reading literatures on learner identity and academic transition, which led to consideration of related factors: learner motivations for choosing a particular course, expectations of that course, and the extent to which the subsequent reality of studying the course matched these expectations. The model was devised as a method of understanding the relationship between these factors, and was used to conduct an initial thematic analysis of individual learner narratives once they had been transcribed. Recurring themes were identified and colour-coded for each of the first five elements of the model, thus allowing identification of patterns (the Stories and Synthesis element) across the narratives for each section. I then conducted a second wave of analysis on the learner narratives and identified six words that appeared significant across the narratives in terms of expressing the transition process: freedom, independence, confidence, maturity, practical and preparation. This aspect of the process is discussed in more detail when the model is evaluated later in this article. 


\section{Table 1: Summary of the MERITS Plus model}

\begin{tabular}{|c|c|}
\hline Motivations & $\begin{array}{l}\text { Why does an individual choose to study A levels or a BTEC, } \\
\text { rather than follow other academic pathways or apply for work } \\
\text { or apprenticeships? What do they perceive to be the value } \\
\text { of such a choice? Are these motivations largely extrinsic or } \\
\text { intrinsic, or a combination of the two? }\end{array}$ \\
\hline Expectations & $\begin{array}{l}\text { What preconceived ideas (if any) might an individual hold } \\
\text { before starting an A level or a BTEC programme of study? } \\
\text { Where do these come from? How do they expect A level or } \\
\text { BTEC lesson content and delivery to differ from GCSE classes? }\end{array}$ \\
\hline Reality & $\begin{array}{l}\text { How does the programme match up to these expectations } \\
\text { in actuality? Has the shift from GCSE to A level/BTEC been } \\
\text { challenging in terms of pedagogical changes? Do students } \\
\text { think that GCSEs have adequately prepared them for the } \\
\text { rigours of studying a Level } 3 \text { qualification? }\end{array}$ \\
\hline Identity & $\begin{array}{l}\text { How do A level or BTEC students describe themselves? Is } \\
\text { there any commonality in how individual students describe } \\
\text { themselves, suggesting a collective identity among different } \\
\text { groups of learners? Do they perceive that their identity may } \\
\text { have changed since becoming an A level/BTEC student, and } \\
\text { if so, in what way? }\end{array}$ \\
\hline Transition & $\begin{array}{l}\text { How effectively do A level/BTEC students feel that: (1) GCSEs } \\
\text { have prepared them for study at Level 3; and (2) A levels/ } \\
\text { BTECs are preparing them for study at higher education? } \\
\text { What examples can they provide of skills they have developed } \\
\text { through the process of moving from GCSE studies to A level/ } \\
\text { BTEC? }\end{array}$ \\
\hline Stories and Synthesis & $\begin{array}{l}\text { How do individual students bring together these feelings and } \\
\text { experiences in order to narrate the story of their academic } \\
\text { transition? Do they use similar words or phrases to suggest a } \\
\text { commonality of experience and identity during the narration } \\
\text { of these stories? }\end{array}$ \\
\hline \multicolumn{2}{|c|}{ Linguistic analysis through identification of keywords in the narratives } \\
\hline \multicolumn{2}{|c|}{ Creation of composite learner profiles } \\
\hline \multicolumn{2}{|c|}{$\begin{array}{l}\text { Use of Bourdieu's thinking tools to consider the implications of the thematic and linguistic } \\
\text { analysis }\end{array}$} \\
\hline
\end{tabular}

\section{Motivations}

The first element of the model, Motivations, examines the factors identified by learners as having impacted upon their reasons for choosing their academic pathway. This recognizes that individuals may be both intrinsically or extrinsically motivated, using Lai's (2011: 4) definition that the former 'is animated by personal enjoyment, interest or pleasure' and the latter is 'governed by reinforcement contingencies' or the perceived consequences of that choice. Much of the literature on learner motivations focuses on particular groups of students, such as working-class or ethnic minority learners, and can be separated into two key issues: learners' failure to achieve the required grades to access higher education, and a lack of ambition to go to university even when appropriate grades are achieved (see, for example, UCAS, 2015; OFFA, 2016; BIS, 2015). While the LITP does not focus on socio-economic factors, this element of the model considers whether inequalities in social mobility can impact upon a learner's 
ability to exert agency in selecting a study path upon leaving school, where they have developed a particular habitus that may - for example - better equip them to succeed in examination-based qualifications.

\section{Expectations}

The second element, Expectations, recognizes that expectations differ from aspirations, as they have a greater grounding in social reality and are 'what an individual believes will happen in the future' (Gorard et al., 2012: 13). Thus, expectations are anchored in the reality of previous educational experiences, which are influential in creating a concrete image of what might happen during the next stage of academic life. The notion of habitus suggests that by the time a learner enters 16-19 education, they already have an idea of where they might fit within this field, and that expectations are determined by 'the perceived structure of opportunity within society' (Khattab, 2015: 734). However, the move to a new field of education can be a positive one: transition also provides an opportunity for transformation, and habitus' 'permanent capacity for reinvention' (Bourdieu, 2004: 63) allows for the possibility of exceeding one's own expectations by successfully adapting to the new field.

\section{Reality}

The LITP understands Reality as participants' narratives of what had happened during and after their move to college, rather than what they had expected to happen. Even allowing for the simplicity of this definition, 'reality' is not a straightforward term of reference; it has been suggested that much of what is considered truth is in fact socially constructed (for example, Searle, 1995), and that when an individual believes they are conveying truths they may instead be acting out particular roles in what is essentially a performance rather than reality (Goffman, 1959). For this reason, the LITP made no claim to present objectively verifiable truths; instead, the study was interested in learners' espoused perceptions of the reality of studying a particular course, aiming for the construction of a view of studying a course from the perspective of those at the heart of the programme. This focus on participants' perceived realities aimed to understand why not all learners succeed in creating the reality that they expect (Könings et al., 2008), and subsequently change course, transfer to another institution, or drop out of education altogether.

\section{Identity}

From the broad range of existing literatures on Identity, the LITP focused on those areas most pertinent to understanding identity through Bourdieu's $(1977,1986,2004)$ thinking tools: ideas around the relationship between agency and structure, the fluid and dialogic nature of identity, and notions of collective identity. Bourdieu (1977) suggests that choices are always underpinned by a sense of agency, but highlights the importance of understanding the limitations of that agency in the context of the possibilities offered by its relation to cultural fields. Another strand of the literature suggests that an individual's sense of self is not fixed, but is influenced both by the longitudinal passing of time and by the different contexts and structures in which that individual operates at any given period. An individual may simultaneously have any number of different identities dependent on contexts (see, for example, Jenkins, 2004), helping understand how individuals have the capacity to adapt to new experiences and environments through the transformative nature of the habitus. The study also drew upon ideas of collective identity to explore the notion that an individual's identity 
is simultaneously about sameness and difference, with 'collective identification evok[ing] powerful imagery of people who are in some respect(s) apparently similar to each other' (ibid.: 79). While ideas such as these are sometimes contested for their neat oversimplification of the complex nature of identity, the LITP aimed to better understand patterns of collective identity seen anecdotally at NCFE through its identification of learner types. The site of the research encourages the physical division of A level and BTEC students through its physical environment - a division that is then maintained by the learners themselves through choosing largely to associate only with those on the same or a similar academic pathway.

\section{Transition}

In light of the argument outlined above that identity is not fixed, the Transition element of the model considered the impact that transition may have upon an individual's identity. The Teaching and Learning Research Programme (Ecclestone, 2007) identifies that 'transition depicts change and shifts in identity and agency as people progress through the education system'. Much of the existing literature suggests that transition is likely to consist of both academic and social change, with Terenzini et al. (1994: 58) noting that the process requires students to 'become integrated into the academic and social systems of a college or university'. In other words, an individual must reconcile their own sense of who they are (and who they would like to be) with the educational structures and pathways available to them. Transition can also be a time of opportunity in terms of establishing a new identity (as seen in Gregory, 2013a), offering the possibility that the process of academic transition can have a positive impact upon individual learner identity despite its challenges. For example, Sirsch (2003) recognizes that the transition process from primary to secondary school offers the opportunity for children to grow and learn by overcoming the challenges posed, highlighting the transformative nature of the habitus and its capacity for positive change and reinvention (Bourdieu, 2004).

\section{Stories and synthesis}

The sixth element of the model - Stories and Synthesis - was added during a pilot study (Gregory, 2013b) to accommodate the larger sample afforded by use of questionnaires and bring together a broader range of narratives (and the subsequently broader range of positioning within the data). This allowed me to begin drawing individual narratives and experiences together into larger groupings, thereby exploring whether a range of student 'types' might exist across the setting regardless of individual course choices.

To this end, the MERITS Plus model also draws upon the tradition of using composite learner profiles. During the LITP, eight fictionalized accounts were created directly from the data collected through the student interviews as a means of illustrating the range of positioning within the individual narratives, making use of an increasingly popular tradition of reportage through fictionalized narrative (see, for example, Clough, 2002). In particular, the use of these profiles draws upon the work of Thomson (2002: xiv) and her 'writerly devices', such as the invention of 'two hypothetical children. They do not exist, but they are not simply fiction: these stories are grounded in my research and they carry the theorization of the production of educational disadvantage that underpins the remainder of the book'.

I adopted this approach in compiling eight 'hypothetical' student profiles through careful use of the original learner narratives in order to ensure stories, like Thomson's, 
were 'grounded in my research'. Each profile was written using the thematic and linguistic analysis already conducted, where recurrent ideas and words in the narratives were colour-coded across the data; for example, when asked about their motivations for choosing their course, a number of the participants said they had originally chosen a different course and/or a different educational provider but that it had not proved to be the right choice. Such comments were highlighted in the same colour across the narratives and were then incorporated into a relevant composite. Where possible, I used the learners' own words in shaping these into cohesive narratives; for example, one participant commented that the BTEC he had enrolled for at NCFE had given him 'another chance', which I adapted slightly to provide the name of the 'Second Chance' composite.

These composite profiles were then distributed in draft form to five members of staff at NCFE who had agreed to participate in a focus group, the transcript of which constituted the second dataset. These participants taught across a wide variety of courses and were invited to discuss the validity of the profiles in light of their professional teaching experience. The composite learner profiles proposed eight different learner 'types' represented in the data collected during the learner narratives: 'The Fresh Start', 'The Practical One', 'The Subject Specialist', 'The Love of Learning', 'The Get Me Where I Need to Go', 'The Make My Family Proud', 'The Not Sure About the Future' and 'The Second Chance' (see Box 1 for full profiles). The effectiveness of these profiles as a method of data presentation is evaluated further later in this article.

\section{Box 1: Composite learner profiles}

\section{'The Fresh Start'}

The Fresh Start has not particularly enjoyed their previous experiences of education. This could be for a number of reasons, either academic or social, but regardless of specifics, this student views college as an opportunity to become someone new, forging a fresh identity outside the familiar environment of secondary school. Familiarity for this learner is not a positive - they have operated in the school environment for five years, and while they themselves have matured and changed, the way they are perceived by others has not. Now old and unsatisfactory friendship groups can be left behind, and new ones formed, meaning Fresh Starts are free to be themselves. Thus, academic choices, while important, come second to the social benefits conferred by college.

\section{'The Practical One'}

The Practical One has successfully completed their secondary school education and achieved satisfactory GCSE grades, which allow them to progress to Level 3 study. However, the school system of assessment through summative examination has not been enjoyable for this student, and although hard work has ensured some measure of achievement, this regime does not play to their strengths. The Practical One prefers projects and coursework, and feels they will thrive in an educational environment where work is assessed continuously and where they will be responsible for managing their own time and workload. For many of these individuals, the skills and abilities being assessed are also perceived as likely to be valuable in the world of work. This student is not worried about the academic transition to Level 3; in fact, they feel their new course is likely to be less of a challenge than all the examinations required at GCSE. 


\section{'The Subject Specialist'}

The Subject Specialist already knows what they are interested in, and sees college as an opportunity to study this subject, or group of subjects, in more detail. The school timetable, packed with a range of lessons reflecting the number of subjects studied at GCSE, was more to be endured than celebrated for its variety, and this student is looking forward to ditching topics of less interest in order to focus on those that matter. This might be in the form of a single subject studied for a BTEC or a cluster of related subjects pursued at A level; either way, this student thinks that the chance to select a single, elective pathway reflects their interests, and therefore their identity as an individual, and that college classes will be populated with likeminded people.

\section{'The Love of Learning'}

For this student, intrinsic motivation is key. Here, the qualification itself is secondary to the knowledge it can provide - this student has a deep desire to study at a deeper level than the schooling system has been able to offer, and develop their academic skills in preparation for a life of learning and cognitive development. School offered some opportunity to learn, but the presence of other students with less desire and focus provided a distraction - an annoyance to be tolerated in large classes where some patently did not want to be there. College will offer a new, more mature environment where students have chosen to attend because they wish to be there, and this atmosphere of academia is one to be looked forward to, even if this student does occasionally worry that the work will be challenging.

\section{'The Get Me Where I Need to Go'}

For this learner, Level 3 study in itself is not necessarily an attraction, although there may be elements of the course that hold some appeal. Instead, the qualification chosen by this student is simply a means to an end. It may be a stepping stone to studying a particular subject at university, but is more often seen as a necessity for this learner's chosen career, perceived as essential or at least highly desirable in connection with this goal. This perception may have come from a variety of sources - friends, family, teachers, the media, university entry requirements - but is deeply engrained and nearly always external. They are going to college because they have been told it is the best thing to do, either because of the status it confers or the qualification to which it leads.

\section{'The Make My Family Proud'}

This learner values their family, and in turn values what their family hold dear. Their parents may well not have studied at Level 3 and certainly did not get the chance to go to university; this student can now put this right by thriving in education and gaining academic success. This success will be demonstrated by going to college and doing well enough to gain entry to higher education, where a good degree will lead to higher status and - presumably - a well-paid career. This learner is happy to follow this path - they want to make their parents proud and, after all, if their parents aspire to such vicarious academic status then it must be worth having. 


\section{'The Not Sure about the Future'}

This learner has yet to find a clear pathway in life, despite the advice imparted by family, teachers and peers. Most do, however, perceive that continuing with their education in some form is likely to be of value in the future, regardless of what this might hold - although some are just buying some time to think about their options. This student is more likely to pick a subject or subjects they enjoy rather than those leading towards a particular career - they want to keep their options open rather than entering a potentially narrow pathway. There may be high extrinsic motivators for this student in the form of their parents, who have made it clear that if they do not do something useful (such as go to college) while they are pondering their future, they can get a job or get out.

\section{'The Second Chance'}

Something, somewhere, has not gone to plan for this learner. Often, an academic choice has been made that proved to be erroneous - a pathway selected that did not, in the end, match the needs and abilities of the learner, or a choice of educational provider where the learner failed to settle and integrate. They may have dropped out of this course part-way through, or remained to the end and failed to achieve the required standard; either way, the course they have chosen now represents another chance. Likely to be a year older than most of their classmates, this learner approaches their new studies with a maturity won from experience and a confidence drawn from knowing they are lucky enough to be on the correct path now.

The final layer of analysis within the MERITS Plus model uses Bourdieu's (1977, 1986, 2004) thinking tools, grouped under headings of fields, games and capital; disposition and habitus; and agency, structure and misrecognition. The use of these tools provided a lens through which to consider the implications of the thematic and linguistic analyses of the learner narratives. As it lies beyond the scope of this article to explore these thinking tools in depth, the following summary focuses on those aspects most pertinent to the LITP's research interests.

\section{Fields, games and capital}

The LITP is located in the field of 16-19 education, and Bourdieu's (1986) notion of capital (and cultural capital in particular) was used in the study to help make sense of why different values are attached to different qualifications, and by whom. Cultural capital - 'which is convertible, on certain conditions, into economic capital and which may be institutionalized in the form of educational qualifications' (Bourdieu, 1986: 47) suggests that educational fields are not level playing surfaces, particularly since capital makes 'the games of society ... something other than simple games of chance offering at every moment the possibility of a miracle (ibid.: 46). For the respondents in the LITP entering the field of 16-19 education, the odds of academic recognition may be automatically limited or enhanced by the choice of a particular 'game' (or educational pathway) conferring a certain kind of cultural capital. Bourdieu (1986) suggests that habitus is revealed through practice, and that objectified cultural capital acquires its own value that may be valid at any one time - a value created previously by earlier social agents. The literature review conducted prior to the LITP (Gregory, 2012) found that A levels were still recognized as being the gold standard (Snapper, 2007) among Level 3 qualifications in a range of literatures and discourses. This suggested that some choices carry a higher value in terms of the cultural capital they can confer, and 
potentially a recognition that those entering certain pathways already possess more cultural capital as a result of their academic success at school. However, the narratives collected during the LITP suggested a new discourse was forming around vocational qualifications, with the BTEC learners talking more positively of the skills they had acquired during the programme in contrast to their A level counterparts. The lens of Bourdieu's thinking tools helped understand the complexities of these narratives: the objectified element of cultural capital means that values are not fixed, and instead are modified as cultural tastes adapt and change, offering the potential for a shift in any given field. The metaphor of field as a site of cultural practice suggests that a field not only comprises rules, rituals and conventions but also consists of the conflict created when individuals or groups of individuals negotiate their place within this site, a process that was identifiable in the learner narratives with the use of the MERITS Plus model.

\section{Disposition and habitus}

Bourdieu's $(1977,2004)$ concepts of habitus and disposition were used to consider how an individual, with their own personal beliefs and experiences, might become assimilated within a wider educational habitus, where a shared sense of disposition is identified with others who have chosen the same study pathway. The notion of habitus suggests that certain habits and dispositions can become part of an individual's identity due to previous experiences and the forms of capital already possessed, thus affecting motivations for choosing the academic pathway to which learners feel they are best suited and limiting true agency. Habitus represents both the way in which individuals develop a sense of self through establishing their own personal attitudes and dispositions, and how these individuals then engage in different forms of practice with others of a similar disposition. This thinking tool has been widely used in a range of disciplines (see, for example, Davey, 2009; Nolan, 2012; Morberg et al., 2012; James et al., 2016; Gopaul, 2015) to examine how individual identities are affected by the process of transition, and to explore why some thrive while others struggle to adapt. However, as the LITP's participants had all succeeded in managing the transition from Level 2 to Level 3 study, this thinking tool was used with a focus on the transformative nature of habitus, which possesses 'permanent capacity for invention' (Bourdieu, 2004: 63). This is a key consideration when studying learners entering a new field and its associated structures, both in terms of what the new field may reveal and what it may add to an individual's existing habitus.

\section{Agency, structure and misrecognition}

Agency (Bourdieu, 1977) refers to the idea that an individual can exercise choice through a sense of intentionality and thereby take some control of their own path in life - when choosing Level 3 study options at the age of 16, for example. However, this sense of individuality and personal autonomy does not exist in isolation, and in practice agency is limited by its relation to the social and cultural structures that organize and give meaning to an individual's environment. These are the existing rules, values and systems by which individuals interpret their place in the world. In other words, while a learner may feel they are exercising free choice when selecting a study programme at 16, this may be a form of misrecognition - a lack of awareness that these choices reflect a role that has already been preassigned. According to Bourdieu (ibid.), choices are always underpinned by a sense of agency, but individual agency will necessarily be limited to the possibilities offered by its relation to cultural fields. Thus, while a 
16-19 learner does have some choice in what and where they elect to study, this is in practice restricted by the options available to them and by the grades achieved at GCSE, highlighting the relationship between an individual's sense of agency and intentionality and the cultural field in which they must operate. This relationship was clear in the data collected in the LITP, with perceived academic ability and predicted examination results identified as key motivations for choosing either A levels or a BTEC.

\section{Methodological challenges for the qualitative researcher}

The LITP collected qualitative data in order to understand participant experiences of academic transition in a real-life context and examine how individuals construct their own versions of reality. Thus, a case study approach was selected, with its focus 'on the way people interpret and make sense of their experiences and the world in which they live' (Holloway, 1997: 1). A case study is a 'strategy for doing research which involves an empirical investigation of a particular contemporary phenomenon within its real life context using multiple sources of evidence' (Robson and McCartan, 2016: 178, drawing on the ideas of Yin, 1981, 1984), allowing the researcher to focus both on 'the particular: a study of that specific case' and 'what kind of generalization is possible from the case', and on 'a phenomenon in context, typically in situations where the boundary between the phenomenon and its context is not clear' (Robson and McCartan, 2016: 179).

This focus on context is highlighted in Geertz's (1973) differentiation between thick and thin description, where the former describes events in relation to their cultural contexts rather than simply describing what has happened; in other words, 'an emphasis [that] is not just on describing what "is" but on explaining how the nature of this phenomenon is closely linked to other aspects of its social context' (Denscombe, 2010: 328). However, the use of a qualitative case study with the aim of capturing and presenting participant voice presents a number of methodological challenges. Due to its heavy reliance upon interpretivism, the case study methodology has sometimes been seen as a '"soft option"' (Robson and McCartan, 2016: 179) compared to more objective, positivist approaches - 'even with good faith and intentions, biased and selective accounts can undoubtedly emerge' (ibid.: 180). This in turn can lead to questionable rigour and/or reliability: 'too many times, the case study investigator has been sloppy, and has allowed equivocal evidence or biased views to influence the direction of the findings and conclusions' (Yin, 1984: 21).

The use of narrative interviews within such a case study approach can present further challenges. Narratives are defined by Riessman and Quinney (2005: 1) as texts 'which have in common a storied form', where 'events are selected, organized, connected, and evaluated as meaningful for a particular audience'. These are now a common method of data collection, as Andrews et al. (2008: 1) identify: 'in the last two decades, narrative has acquired an increasingly high profile in social research'. Despite this popularity, much of the literature on the subject highlights the potential complications in adopting this approach to research. Czarniawska (2004: 5) notes that 'in order to understand their own lives people put them into narrative form' - in other words, to make sense of our own experiences, we turn them into stories that may be shared with others. This process of converting life experiences into narrative is not necessarily a straightforward one: Czarniawska (ibid.), calling upon the work of Davies and Harré (1991), identifies that 'we are never the sole authors of our own narratives; in every conversation a positioning takes place which is accepted, rejected or improved upon by the partners in the conversation'. 
This dialogic nature of narrative, suggesting that meanings are jointly constructed, is highlighted in much of the literature on the use of narratives (see, for example, Holland and Lave, 2001). This calls into question the impact of asymmetric power relationships on this particular methodological approach. I was a teacher at the NCFE at the time of the research, and while not all of the participants were taught by me, all were aware of my position of relative authority within the college. Data collected through such methods can also present issues of fidelity, with responses constructed within a particular moment and not necessarily representing 'truth'. However, as previously stated, the LITP made no claim to establish objectively verifiable truths, and instead sought to present participants' own versions of the transition process. Similarly, the use of the model aimed to mitigate the power imbalance and the potential for researcher bias inherent in the narrative process by using a framework developed from a wide range of literatures to analyse the transcripts in the same way for all participants, regardless of academic pathway or professional relationship with the researcher. The three questions asked in the interviews about motivations, expectations and the reality of the course were all directly linked to the LITP's research questions, and the prompts that were available should participants need them during the interview had been written by students at NCFE during one of the pilot studies.

The use of qualitative interviews also poses the question of how to analyse the data in such a way as to be able to relate individual narratives to broader social contexts. In other words, how can the researcher preserve the integrity of participant voice collected via qualitative methods such as narrative interviews, while conducting a systematic, rigorous, meaningful and unbiased analysis? The remainder of this article outlines how conceptual frameworks may be used to address this question, with a detailed consideration of the role and effectiveness of the MERITS Plus model in my own research.

\section{The use of conceptual frameworks in qualitative research}

Despite the challenges outlined above, as the LITP was primarily a study of identity and howyoung people perceive themselves in an educational setting, I wanted to understand their experiences of academic transition and how they narrated the choices they had made. Furthermore, I was interested in the language participants used to narrate their experiences, and whether the two cohorts narrated their experiences differently. It was imperative to find a balance between fidelity in representing those words while also examining the significance of these narratives within their wider contexts, and thus the MERITS Plus model was developed as a method of attempting to do so. The ability to place a clear, coherent structure on narratives is needed if the researcher is to counteract what Andrews et al. (2008: 1) identify as one of the complicating factors in a narrative approach, where 'there are no self-evident categories on which to focus as there are with content-based thematic approaches'. Riessman and Quinney (2005: 2) echo this sentiment, pointing out that although approaches to narrative research vary enormously, the researcher must be very clear in how they have made sense of the material they have collected, because 'narratives do not speak for themselves or have unanalysed merit; they require interpretation when used as data in social research'.

The use of conceptual frameworks, defined by Miles et al. (2014: 20) as a means of explaining 'the main things to be studied - the key factors, constructs or variables - and the presumed relationships among them', has enjoyed a growing emphasis in doctoral research across a range of disciplines in recent years (Berman, 2013). While 
some literature uses the terms 'conceptual framework' and 'theoretical framework' interchangeably, this article makes a distinction between the two in adopting the term 'conceptual' to represent the 'process of personal conceptualisation that is the basis of doctoral study' (ibid.: 2), with the MERITS Plus model created from the reading of a wide range of existing literatures. This approach supports the distinction made by Parahoo (2006), who suggests that theoretical frameworks make use of one underpinning theory, while conceptual frameworks may use different elements and concepts from a range of theories in helping guide the researcher. The MERITS Plus model draws upon ideas from existing literatures on learner motivations, expectations, perceptions, identity and transition, as well as making use of Bourdieu's (1977, 1986, 2004) thinking tools.

This article does, however, use the terms 'framework' and 'model' interchangeably. The MERITS Plus model is a descriptive tool identifying interrelated elements as part of a systematic framework developed to identify key concepts in the literature, direct the research design, and make relationships explicit and cohesive (Leshem and Trafford, 2007). Thus, a conceptual framework provides a 'logical structure of connected concepts that help provide a picture or visual display of how ideas in a study relate to one another' (Grant and Osanloo, 2014: 17).

\section{A critical evaluation of the MERITS Plus model}

As already discussed, the model was developed as a means of capturing the voices of the participants through their narratives, and in finding a balance between fidelity in representing those words while examining the significance of the narratives within their wider contexts. The LITP was not longitudinal in nature, with single narrative interviews conducted with participants during the space of one term. This necessitates consideration of whether this kind of snapshot of a particular moment can ever capture the dynamic processes at work and the fluid nature of identity. To this end, the model offers a multilayered approach, with a second wave of linguistic analysis used in order to go beyond thematic codification and consider the possibility that language exists to 'support the performance of social activities and social identities and to support human affiliation within cultures, social groups, and institutions' (Gee, 2005: 1). This was examined by looking at the individual words used by the learners and considering whether the language choices selected in the narratives by each learner reflected any cultural or social affiliation. I noted whether the six keywords identified as occurring most regularly during the narratives were used with greater frequency by one of the groups of learners over the other, and whether words appeared to have different meanings for different learners within the context of the narratives in which they were used. Gee (ibid.) defines 'social identities' as 'different ways of participating in different sorts of social groups, cultures and institutions, for example ways of being a "good student"', and while the LITP does not claim to have attempted a full linguistic analysis, I wanted to ensure that the narrative data were handled as 'discourse ... language viewed in a certain way, as part of the social process' (Fairclough, 2015: 7).

The use of the composite learner profiles was also designed to examine the nature of these 'social identities' by illustrating the range of learner types within an educational setting (in this case, NCFE), and exploring the way that individual identities might coexist alongside group or collective identities. The participants in the focus group conducted as part of the LITP agreed they had encountered all eight of the learner types across both BTEC and A level students - 'I recognize everyone ... it's just the proportion that varies, that's all' (Teacher 1); 'I've definitely seen them all ... I can 
see my students evenly across them all' (T2). Some participants, particularly those with experience of teaching both vocational and A level qualifications, felt some categories of learner were more prevalent on particular pathways - 'I see more Second Chances and Get Me Where I Need to Go in my BTEC students' (T3); [in response] 'Yes, I've never seen a Second Chance where a voc [vocational] student has gone to A level ... A level students are more Love of Learning, whilst BTEC are more the Practical One and Subject Specialists" (T1).

However, participants agreed that the differences were rarely clear cut, and that no type was definitively identified with one particular cohort other than the Second Chance: 'lots of the vocational students are those on their second chance' (T2); 'In my second year BTEC group over half originally did A levels, so there are lots of second chancers, and the number is rising every year' (T3). Similarly, while participants agreed that the eight composite profiles provided a fair representation of the types of students both at NCFE and at other educational institutions in which they had worked, two subcategories were suggested - 'success stories', and 'students who miss school'. It was felt that rather than form a distinct category of their own, each of these can appear across all eight of the existing composites. The discussion also recognized the messy nature of reality, and that rather than fit neatly into one group, some students bridge more than one category, although no particular examples were given: 'I don't think there are any more groups [than the eight profiles provided] but many students are a bit of several' (T3).

These findings raise the question of how the integrity of individual participant voice can be balanced with the use of fictionalized narratives that categorize the participants: composite profiles run the risk of losing some of the individuality of participant narratives and the sense of voice within them. The use of the MERITS Plus model as a conceptual framework aimed both to allow the analysis of the narratives as individual stories, and to understand them as products of particular social contexts. However, it can still be argued that the process of analysis using the model outlined in this article is too reductive. Despite the multilayered approach to analysis offered by the model, the fact remains that any process of analysis is a potentially restrictive process that can constrain how the data are treated - in this case, by organizing the individual narratives into specific categories that are listed in a particular order, and then into wider stories by identifying similarities with other narratives. It must also be acknowledged that while the MERITS Plus model was developed from a wide range of reading, some of the ideas adopted in the model are contested, particularly those around identity and transition, and that by using Bourdieu's ideas as a thinking tool, the study is exploring the data from a specific viewpoint.

However, the model clearly identifies the literatures that have been used in its development, and has been used with flexibility and transparency. The model has already undergone a number of changes during its development, beginning as a fiveelement conceptual framework used to conduct thematic analysis during a pilot study. A subsequent pilot study resulted in the addition of the sixth element, Stories and Synthesis, with the layer of Bourdieusian analysis added during the main fieldwork for the LITP, specifically to trouble the neat patterns of the original model and address the anomalies raised. These developments do raise the question of how the model might continue to develop and change in order to reflect the fluid and dialogic nature of identity, and what form that might take. Further research is clearly needed in order for the model's continued development, presenting the risk that the use of such a framework could lead to researchers making assumptions or second guessing what that research might say. These are arguments that could be levelled at any conceptual 
framework, however, and serve as a reminder of the importance of researcher reflexivity in all forms of research, but particularly that involving qualitative data.

\section{Conclusion}

This article has considered the use of the MERITS Plus model, a conceptual framework developed in order to examine the impact of academic transition on learner identity during doctoral research in a further education college. While the use of narratives in research remains potentially problematic, the use of the framework did allow for systematic analysis of narrative data through sequential analysis: the breaking down of each narrative into sections that can be coded and then organized by theme (Holloway and Wheeler, 2002). However, while the original MERITS model revealed thematic and linguistic trends within the data, any approach using an analytical framework is a reductive process and can risk concealing more than it reveals. The initial thematic analysis completed during the LITP raised questions about the data that necessitated a different approach in addressing their complexities, and the use of Bourdieu's thinking tools in combination with the original MERITS model to form the MERITS Plus model gave an additional layer to the analysis, providing structure but also the flexibility needed when dealing with the messy nature of reality.

This reflects the findings of other researchers, such as Williams et al. (2010: 39), whose research into the identities revealed during biographical narratives provided by mathematics students concluded that ' discursive and narrative analyses are inadequate to understanding the formation of identity in practice: we need a unit of analysis that bounds the engagement of the self in social practice and in narrative work'. 'In practice' emphasizes the fluid and dialogic nature of identity, which alters both over time and in relation to different contexts and structures, rather than being a fixed reference point. In this regard, thematic analysis of learner narratives was both helpful and restrictive, with each interview capturing an individual at a particular moment in time and reflecting the dynamic nature of a developing identity. Without the use of Bourdieu's thinking tools, the MERITS-driven analysis of the narratives can identify the 'what' and the 'how' but not fully explain the 'why', as a horizontal discussion of patterns alone fails to locate individuals within the social structures and practices that have influenced - and continue to influence - the construction of their own espoused identities.

\section{Notes on the contributor}

Elizabeth Gregory is a research supervisor at the University of Manchester, working with dissertation students on the MA Teach First Leadership programme. Prior to this, she taught for 14 years in the further education sector, first as an A level teacher, and later as programme lead and lecturer on a range of education-based undergraduate courses. She completed her EdD part-time through the University of Manchester between 2011 and 2017.

\section{References}

Andrews, M., Squire, C. and Tamboukou, M. (2008) Doing Narrative Research. London: Sage.

AoC (Association of Colleges) (2014) College Funding and Finance. London: Association of

Colleges. Online. https://tinyurl.com/wueopts (accessed 14 November 2019).

Berman, J. (2013) 'Utility of a conceptual framework within doctoral study: A researcher's reflections'. Issues in Educational Research, 23 (1), 1-18. 
BIS (Department for Business, Innovation and Skills) (2015) Fulfilling Our Potential: Teaching excellence, social mobility and student choice. London: Department for Business, Innovation and Skills.

Bourdieu, P. (1977) 'Cultural reproduction and social reproduction'. In Karabel, J. and Halsey, A.H. (eds) Power and Ideology in Education. New York: Oxford University Press, 487-511.

Bourdieu, P. (1986) 'The forms of capital'. In Richardson, J.G. (ed.) Handbook of Theory and Research for the Sociology of Education. Westport, CT: Greenwood Press, 241-58.

Bourdieu, P. (1991) Language and Symbolic Power. Ed. Thompson, J.B. Trans. Raymond, G. and Adamson, M. Cambridge, MA: Harvard University Press.

Bourdieu, P. (2004) In Other Words: Essays towards a reflexive sociology. Trans. Adamson, M. Cambridge: Polity Press.

Clough, P. (2002) Narratives and Fictions in Educational Research. Buckingham: Open University Press.

Czarniawska, B. (2004) Narratives in Social Science Research. London: SAGE Publications.

Davey, G. (2009) 'Using Bourdieu's concept of habitus to explore narratives of transition'. European Educational Research Journal, 8 (2), 276-84.

Davies, B. and Harré, R. (1991) 'Contradiction in lived and told narratives'. Research on Language and Social Interaction, 25 (1-4), 1-35.

Denscombe, M (2010) The Good Research Guide: For Small-Scale Social Research Projects (4th ed.). Maidenhead: Open University Press

Ecclestone, K. (2007) 'Lost and found in transition: The implications of "identity", "agency" and "structure" for educational goals and practices'. Keynote presentation to Researching Transitions in Lifelong Learning Conference, University of Stirling, 22-4 June.

Fairclough, N. (2015) Language and Power. London: Routledge.

Gee, J. (2005) An Introduction to Discourse Analysis: Theory and method. Abingdon: Routledge.

Geertz, C. (1973) The Interpretation of Cultures: Selected essays. New York: Basic Books.

Goffman, E. (1959) The Presentation of Self in Everyday Life. London: Penguin.

Gopaul, B. (2015) 'Inequality and doctoral education: Exploring the "rules" of doctoral study through Bourdieu's notion of field'. Higher Education, 70 (1), 73-88.

Gorard, S., See, B.H. and Davies, P. (2012) The Impact of Attitudes and Aspirations on Educational Attainment and Participation. York: Joseph Rowntree Foundation.

Grant, C. and Osanloo, A. (2014) 'Understanding, selecting, and integrating a theoretical framework in dissertation research: Creating the blueprint for your "house"'. Administrative Issues Journal: Connecting Education, Practice, and Research, 4 (2), 12-26.

Gregory, E. (2012) 'Understanding A-levels and the issues affecting the perception of their status as a benchmark of excellence: A literature review'. Unpublished research paper for the EdD Programme, School of Education, University of Manchester, May 2012.

Gregory, E. (2013a) 'An investigation into learner perceptions of the A-Level qualification, both at the start and the mid-way point of their studies'. Unpublished research paper for the EdD Programme, School of Education, University of Manchester, May 2013.

Gregory, E. (2013b) 'Research methods in action: Towards a collective identity - a study of learners' self-perception in the FE environment'. Unpublished research paper for the EdD Programme, School of Education, University of Manchester, October 2013.

Holland, D. and Lave, J. (eds) (2001) History in Person: Enduring struggles, contentious practice, intimate identities. Oxford: James Currey.

Holloway, I. (1997) Basic Concepts for Qualitative Research. Oxford: Blackwell Science.

Holloway, I. and Wheeler, S. (2002) Qualitative Research in Nursing. 2nd ed. Oxford: Blackwell Science.

James, N., Busher, H. and Suttill, B. (2016) "'We all know why we're here": Learning as a community of practice on Access to HE courses'. Journal of Further and Higher Education, 40 (6), 765-79.

Jenkins, R. (2004) Social Identity. Abingdon: Routledge

Khattab, N. (2015) 'Students' aspirations, expectations and school achievement: What really matters?'. British Educational Research Journal, 41 (5), 731-48.

Könings, K.D., Brand-Gruwel, S. and Van Merriënboer, J.J.G. (2008) 'Does a new learning environment come up to students' expectations? A longitudinal study'. Journal of Educational Psychology, 100 (3), 535-48.

Lai, E.R. (2011) Motivation: A literature review: Research report. London: Pearson. Online. https://tinyurl.com/wxq6yc9 (accessed 15 November 2019).

Leshem, S. and Trafford, V. (2007) 'Overlooking the conceptual framework'. Innovations in Education and Teaching International, 44 (1), 93-105. 
Miles, M.B., Huberman, A.M. and Saldaña, J. (2014) Qualitative Data Analysis: A methods sourcebook. 3rd ed. Thousand Oaks, CA: SAGE Publications.

Morberg, S., Lagerström, M. and Dellve, L. (2012) 'The school nursing profession in relation to Bourdieu's concepts of capital, habitus and field'. Scandanavian Journal of Caring Sciences, 26 (2), 355-62.

Nolan, K. (2012) 'Dispositions in the field: Viewing mathematics teacher education through the lens of Bourdieu's social field theory'. Educational Studies in Mathematics, 80 (1-2), 201-15.

OFFA (Office for Fair Access) (2016) Outcomes of Access Agreement Monitoring for 2014-15. Bristol: Office for Fair Access.

Parahoo, K. (2006) Nursing Research: Principles, process and issues. 2nd ed. Basingstoke: Palgrave Macmillan.

Riessman, C.K. and Quinney, L. (2005) 'Narrative in social work: A critical review'. Qualitative Social Work, 4 (4), 391-412.

Robson, C. and McCartan, K. (2016) Real World Research: A resource for users of social research methods in applied settings. 4th ed. Chichester: Wiley.

Searle, J.R. (1995) The Construction of Social Reality. New York: Free Press.

Sirsch, U. (2003) 'The impending transition from primary to secondary school: Challenge or threat?' International Journal of Behavioural Development, 27 (5), 385-95.

Snapper, G. (2007) 'Beyond Curriculum 2000: Some national and international perspectives on A Level English Literature'. International Journal of Adolescence and Youth, 14 (1), 13-29.

Terenzini, P.T., Rendon, L.I., Upcraft, M.L., Millar, S.B., Allison, K.W., Gregg, P.L. and Jalomo, R. (1994) 'The transition to college: Diverse students, diverse stories'. Research in Higher Education, 35 (1), 57-73.

Thomson, P. (2002) Schooling the Rustbelt Kids: Making the difference in changing times. Stoke-onTrent: Trentham Books.

UCAS (Universities and Colleges Admissions Service) (2015) End of Cycle Report 2015: UCAS analysis and research. Cheltenham: Universities and Colleges Admissions Service. Online. www.ucas.com/sites/default/files/eoc-report-2015-v2.pdf (accessed 25 October 2016).

Williams, J., Black, L., Davis, P., Hernandez-Martinez, P., Hutcheson, G., Nicholson, S., Pampaka, M. and Wake, G. (2010) 'Pedagogies for social diversity and difference: Section 2 - Keeping open the door to mathematically demanding programmes in further and higher education: A cultural model of value'. In David, M. (ed.) Improving Learning by Widening Participation in Higher Education. London: Routledge, 109-23.

Yin, R.K. (1981) 'The case study as a serious research strategy'. Science Communication, $3(1), 97-114$.

Yin, R.K. (1984) Case Study Research: Design and methods. Beverly Hills, CA: SAGE Publications. 